\title{
OBTENÇÃO DE PROTOPLASTOS DE Botryosphaeria sp.
}

\section{ISOLATION OF Botryosphaeria sp. PROTOPLASTS}

\author{
Carlos Eduardo Marchi', Mírian de Freitas Borges², Sérgio Hermínio \\ Brommonschekel $^{3}$
}

1 Autor para contato: Embrapa Gado de Corte, Campo Grande, MS, Brasil; fax: (67) 3368-2150; e-mail: cemarchi@cnpgc.embrapa.br

2 Superintendência Federal de Agricultura-MS, Campo Grande, MS

3 Universidade Federal de Viçosa - UFV, Departamento de Fitopatologia, Viçosa, MG

Recebido para publicação em 06/09/2006

Aceito para publicação em 20/12/2006

\section{RESUMO}

A protoplastização constitui ferramenta importante no estudo de fungos filamentosos. Acredita-se que a obtenção de protoplastos de Botryosphaeria spp., ascomicetos causadores de cancro em Eucalyptus spp., possa constituir caminho para aumentar o conhecimento sobre esses patógenos. Por isso, visando a obtenção de protoplastos de Botryosphaeria sp., avaliou-se a eficiência dos seguintes sistemas líticos: Glucanex (Novo Nordisk Ltd.), Lysing Enzymes (Sigma Chemicals Co.), Cellulase Onozuka R-10 (Yakult Biochemical Co. Ltd.), Cellulase (Sigma Chemicals Co.), Driselase (Sigma Chemicals Co.), Glucanex + Cellulase Onozuka R10, Lysing Enzymes + Cellulase Onozuka R10, Driselase + Cellulase Onozuka R10 e Lysing Enzymes + Glucanex. Detectado o sistema lítico mais eficiente, avaliaram-se diferentes concentrações de enzimas. Adicionalmente, foram analisados estabilizadores osmóticos à base de $\mathrm{MgSO}_{4}, \mathrm{KCl}, \mathrm{NaCl}$, Sorbitol e Sacarose, bem como tempos de protoplastização (1 a 6 horas). Maior produção de protoplastos foi obtida com o uso simultâneo de Glucanex e Lysing Enzymes. O uso de 7,5 mg de cada complexo enzimático, em 3,5 mL de estabilizador osmótico, resultou em maior liberação de protoplastos. O melhor estabilizador osmótico foi $\mathrm{MgSO}_{4}$ a 1,2 $\mathrm{M} / \mathrm{NaH}_{2} \mathrm{PO}_{4}$ a $0,01 \mathrm{M}(\mathrm{pH}=5,8)$. A produção de protoplastos foi monitorada a cada 60 minutos, e foi maior com incubação por 4 horas. Os protoplastos obtidos foram aptos a regenerar e reverter à forma hifálica quando plaqueados em meio de regeneração.

Palavras-chave: protoplastização, cancro, Eucalyptus sp. 


\begin{abstract}
Protoplasts are important biological tools in the research of filamentous fungi. The isolation of Botryosphaeria spp. protoplasts, etiological agents of canker in Eucalyptus spp., may be a way to understand these pathogens. Thus, in order to obtain Botryosphaeria sp. protoplasts, we evaluated the efficiency of the lytic systems Glucanex (Novo Nordisk Ltd.), Lysing Enzymes (Sigma Chemicals Co.), Cellulase Onozuka R-10 (Yakult Biochemical Co. Ltd.), Cellulase (Sigma Chemicals Co.), Driselase (Sigma Chemicals Co.), Glucanex + Cellulase Onozuka R10, Lysing Enzymes + Cellulase Onozuka R10, Driselase + Cellulase Onozuka R10 and Lysing Enzymes + Glucanex. When the most efficient lytic system had been detected different concentrations of enzymes were analyzed. Additionally, osmotic buffers of $\mathrm{MgSO}_{4}, \mathrm{KCl}, \mathrm{NaCl}$, Sorbitol and Sucrose were analysed and their digestion time (1 to 6 hours) was established.The highest production of protoplasts was obtained when Glucanex and Lysing Enzymes were used simultaneously. The best protoplast yields were obtained with $7.5 \mathrm{mg}$ of each enzyme in $3.5 \mathrm{~mL}$ of the buffer. The best osmotic buffer was $\mathrm{MgSO}_{4}$ at $1.2 \mathrm{M} / \mathrm{NaH}_{2} \mathrm{PO}_{4}$ at $0.01 \mathrm{M}(\mathrm{pH}=5.8)$. The protoplast production, which was monitored every 60 minutes, increased after 4 hours of incubation. When cultivated in regeneration media, the protoplasts were able to regenerate and revert to their hyphalic form.
\end{abstract}

Key words: protoplastization, canker, Eucalyptus sp.

\section{Introdução}

Botryosphaeria spp. Ces. \& De Not. ocorrem endofiticamente em Eucalyptus spp., mas também estão associadas ao cancro do eucalipto. O cancro de Botryosphaeria é uma das mais sérias doenças de Eucalyptus spp. na África do Sul (TPCP, 2002). Na Austrália, Botryosphaeria sp. é considerado ameaça significativa para a produção e sustentabilidade das plantações de Eucalyptus, sobretudo devido ao aumento da uniformidade genética das plantas (Slippers et al., 2004).

As espécies de Botryosphaeria constantemente associadas ao cancro do eucalipto no Brasil são Botryosphaeria ribis Grossenb. \& Duggar e Botryosphaeria rhodina (Berk. \& M.A. Curtis) Arx (Krugner \& Auer, 1997). O cancro de Botryosphaeria érelevante em cultivos onde ocorre deficiência de boro, relatada como fator de predisposição ao patógeno (Silveira \& Higashi, 2003). Tal estresse nutricional tem sido comum nos plantios de Eucalyptus citriodora (Silveira et al., 1998). A doença ocorre com freqüência nos plantios sob solo arenoso no Estado de São Paulo (Krugner \& Auer, 1997; Silveira et al., 1998).

O limitado conhecimento acerca da patogênese de Botryosphaeria spp. e dos fatores que afetam o seu desenvolvimento têm dificultado o estabelecimento de estratégias específicas para o manejo da doença (Krugner \& Auer, 1997).

A protoplastização de Botryosphaeria spp. é um dos caminhos que podem levar à melhor compreensão desses patógenos. Com a obtenção de protoplastos de Botryosphaeria spp., isto é, células artificialmente desprovidas de parede, seria possível, por exemplo, estabelecer simples e práticos sistemas de transformação genética. Mutantes com patogenicidade alterada poderiam ser obtidos, possibilitando a clonagem e análise de genes relacionados à patogênese. Adicionalmente, os protoplastos possibilitariam a determinação do cariótipo eletroforético das 
espécies e isolados fúngicos envolvidos com o cancro do eucalipto, e conseqüentemente inferir sobre a participação do polimorfismo cromossômico como fonte de variabilidade patogênica na relação patógenohospedeiro.

Diante das perspectivas apresentadas, objetivouse estabelecer protocolo para a produção de protoplastos de Botryosphaeria sp., analisando tipos e concentrações dos sistemas líticos, tipos de estabilizadores osmóticos e tempos de protoplastização.

\section{Material e Métodos}

\section{Cultivo de Botryosphaeria sp.}

O isolado de Botryosphaeria sp., obtido de planta de Eucalyptus sp. infectada, foi rotineiramente cultivado em meio de cultura BDA (batata-dextroseágar) por 5 a 7 dias a $28^{\circ} \mathrm{C}$, no escuro. A preservação do isolado em curto prazo foi feita por meio de repicagens sucessivas.

\section{Obtenção dos protoplastos de Botryosphaeria sp.}

Para o isolamento de protoplastos, fragmentos miceliais de Botryosphaeria sp. foram distribuídos sobre folha de papel celofane estéril, acondicionada em placas de Petri contendo meio BDA. Estas placas foram incubadas a $28^{\circ} \mathrm{C}$, no escuro, por 17 horas. $\mathrm{O}$ micélio obtido foi raspado com o auxílio de espátula.

O procedimento padrão para a protoplastização foi a adição do sistema lítico em 3,5 mL de estabilizador osmótico contendo aproximadamente 80 mg de micélio fresco. Esta mistura foi agitada $(100 \mathrm{rpm})$ a $28-30^{\circ} \mathrm{C}$, por tempo variando de 1 a 6 horas.

Para garantir maior confiabilidade aos resultados, todos os fatores (tipo e concentração de enzimas; estabilizador osmótico e tempo de digestão) foram analisados em dois ensaios independentes, e cada tratamento foi aplicado em quatro unidades experimentais (erlenmeyer $25 \mathrm{~mL}$ ). Os protoplastos foram observados ao microscópio e quantificados em câmara de Neubauer.

\section{Digestão do micélio}

Foram testados os sistemas líticos: 1 - Controle (sem enzima lítica); 2 - Glucanex (Novo Nordisk Ltd.); 3 - Lysing Enzymes (Sigma Chemicals Co.); 4 Cellulase Onozuka R-10 (Yakult Biochemical Co. Ltd.); 5 - Cellulase (Sigma Chemicals Co.); 6 Driselase (Sigma Chemicals Co.); 7 - Glucanex + Cellulase Onozuka R10; 8 - Lysing Enzymes + Cellulase Onozuka R10; 9 - Driselase + Cellulase Onozuka R10; e 10 - Lysing Enzymes + Glucanex. Quinze miligramas de enzima foram misturadas ao estabilizador osmótico $\mathrm{MgSO}_{4}$ a 1,2 M / $\mathrm{NaH}_{2} \mathrm{PO}_{4}$ a $0,01 \mathrm{M}(\mathrm{pH}=5,8)$. Quando em combinações, as enzimas foram usadas em proporções iguais $(7,5 \mathrm{mg}$ de cada enzima). A protoplastização foi conduzida por 4 horas.

\section{Concentração da enzima lítica}

Para estabelecer a melhor relação massa micelial/ enzima, seguindo os procedimentos descritos anteriormente, foram preparadas misturas para a digestão com diferentes quantidades (mg) do sistema enzimático que liberou o maior número de protoplastos. A protoplastização foi efetuada por 4 horas, utilizando-se o estabilizador osmótico $\mathrm{MgSO}_{4}$ a 1,2 $\mathrm{M}$ / $\mathrm{NaH}_{2} \mathrm{PO}_{4}$ a $0,01 \mathrm{M}(\mathrm{pH}=5,8)$.

\section{Tipos de estabilizadores osmóticos}

Verificou-se a eficiência de estabilizadores osmóticos: 1 - Controle (água destilada); 2 - $\mathrm{MgSO}_{4}$ a 1,2 M / $\mathrm{NaH}_{2} \mathrm{PO}_{4}$ a $0,01 \mathrm{M}(\mathrm{pH}=5,8) ; 3-\mathrm{KCl}$ a $0,7 \mathrm{M}$ / $\mathrm{NaH}_{2} \mathrm{PO}_{4}$ a $0,1 \mathrm{M}(\mathrm{pH}=5,9) ; 4-\mathrm{NaCl}$ a $0,8 \mathrm{M}$ / $\mathrm{NaH}_{2} \mathrm{PO}_{4}$ a $0,1 \mathrm{M}(\mathrm{pH}=5,8) ; 5$ - Sorbitol a $0,6 \mathrm{M} /$ $\mathrm{Na}_{2} \mathrm{HPO}_{4}$ a $0,1 \mathrm{M}(\mathrm{pH}=8,0)$ e 6 - Sacarose $20 \%$ / EDTA a $50 \mathrm{mM} /$ citrato tri-sódico a $20 \mathrm{mM}(\mathrm{pH}=$ 8,0). A protoplastização foi efetuada por 4 horas, utilizando-se o binômio sistema enzimático/concentração mais eficiente.

\section{Tempos de exposição ao sistema enzimático}

Detectada a combinação sistema enzimático/ concentração/estabilizador osmótico mais eficiente, monitorou-se a protoplastização em função do tempo de incubação (1 a 6 horas). A cada hora, frações da suspensão de protoplastos foram retiradas assepticamente de cada repetição, com micropipeta, e quantificadas em câmara de Neubauer. 


\section{Resultados}

\section{Digestão do micélio}

A liberação de protoplastos de Botryosphaeria sp. foi influenciada pelo sistema enzimático. Nos dois ensaios, observou-se a mesma tendência para a eficiência dos tratamentos (Figura 1). Menor número de protoplastos foi obtido quando Driselase + Cellulase Onozuka R10, Cellulase, Driselase ou Cellulase Onozuka R10 foram utilizadas.

O micélio de Botryosphaeria sp. foi sensível a Glucanex, e em menor grau a Lysing Enzymes.
Contudo, a combinação desses sistemas líticos constituiu o tratamento mais eficiente na protoplastização do fungo. No segundo ensaio, a mistura resultou em incremento na liberação de protoplastos de aproximadamente 37\%, em relação à Glucanex isolada (Figura 1). Em contrapartida, não foram evidenciados benefícios com a adição de Cellulase Onozuka R10 nos sistemas líticos compostos por Glucanex, Lysing Enzymes ou Driselase. Pelo contrário, no caso de Glucanex, em ambos os ensaios, agindo isoladamente promoveu maior liberação de protoplastos do que em combinação com a celulase.

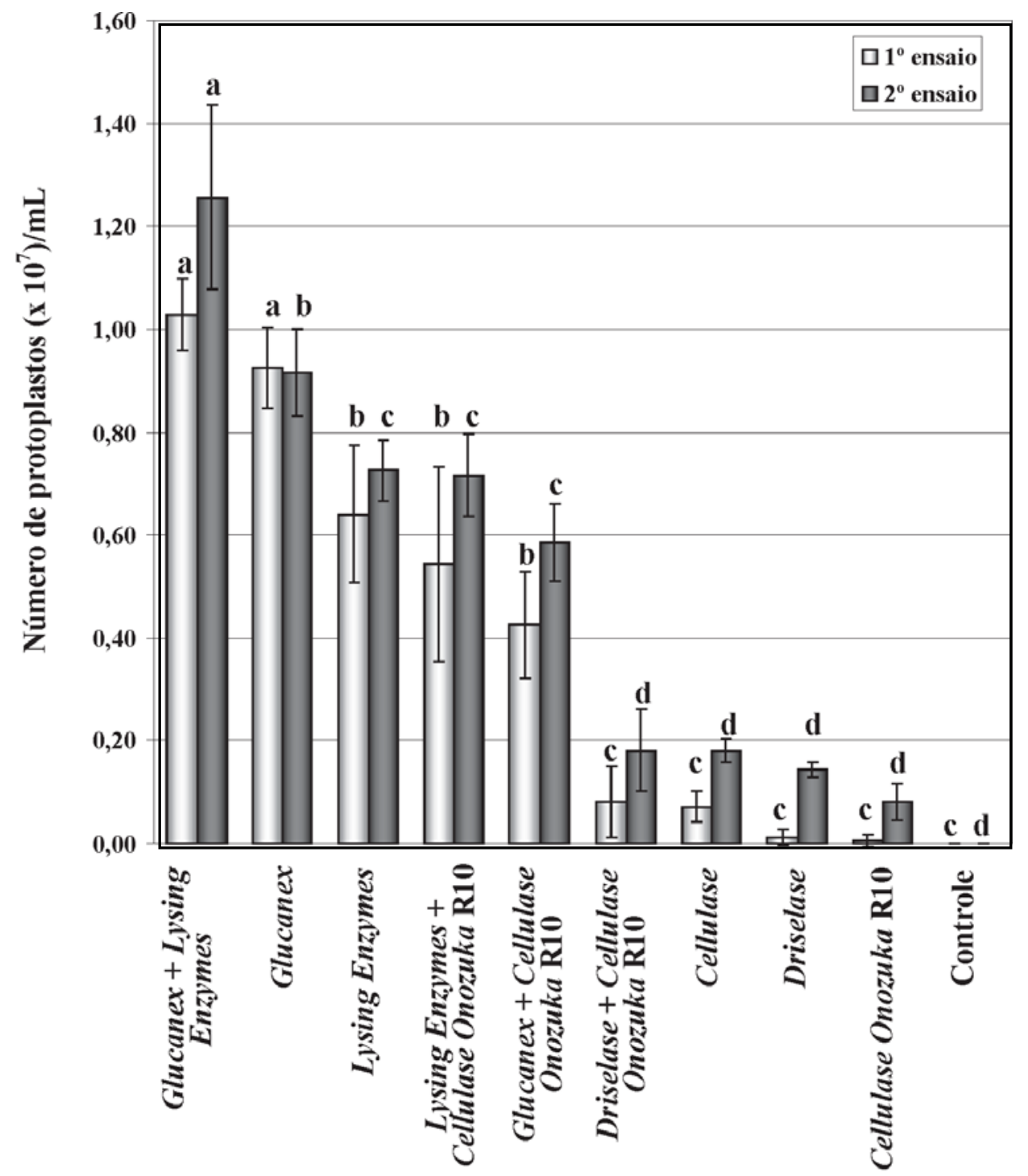

Sistema enzimático

Figura 1 - Número de protoplastos de Botryosphaeria sp. obtidos com diferentes sistemas enzimáticos. Barras representam o desvio padrão. Em cada ensaio, tratamentos com a mesma letra não diferem pelo teste de Tukey a 5\%. 


\section{Concentração da enzima lítica}

O efeito da concentração enzimática na protoplastização de Botryosphaeria sp. foi testado com base na combinação Glucanex-Lysing Enzymes. Foi verificado que a liberação de protoplastos foi influenciada pela concentração enzimática, a qual variou de 2,5 a 15 mg para cada enzima (Figura 2).

Em ambos os ensaios, maior número de protoplastos foi liberado quando o sistema lítico foi composto por $15 \mathrm{mg}$ de enzimas (7,5 mg de Glucanex + 7,5 mg de Lysing Enzymes). Tal concentração permitiu a obtenção de 1,10 e $1,70 \times 10^{7}$ protoplastos/mL no primeiro e segundo ensaio, respectivamente. À medida que o sistema enzimático ficou mais concentrado, houve redução da eficiência de protoplastização. A média dos ensaios foi reduzida para $0,90 \times 10^{7}$ protoplastos $/ \mathrm{mL}$ quando se utilizou $30 \mathrm{mg}$ de enzimas, ou seja, $15 \mathrm{mg}$ de Glucanex + 15 mg de Lysing Enzymes (Figura 2).

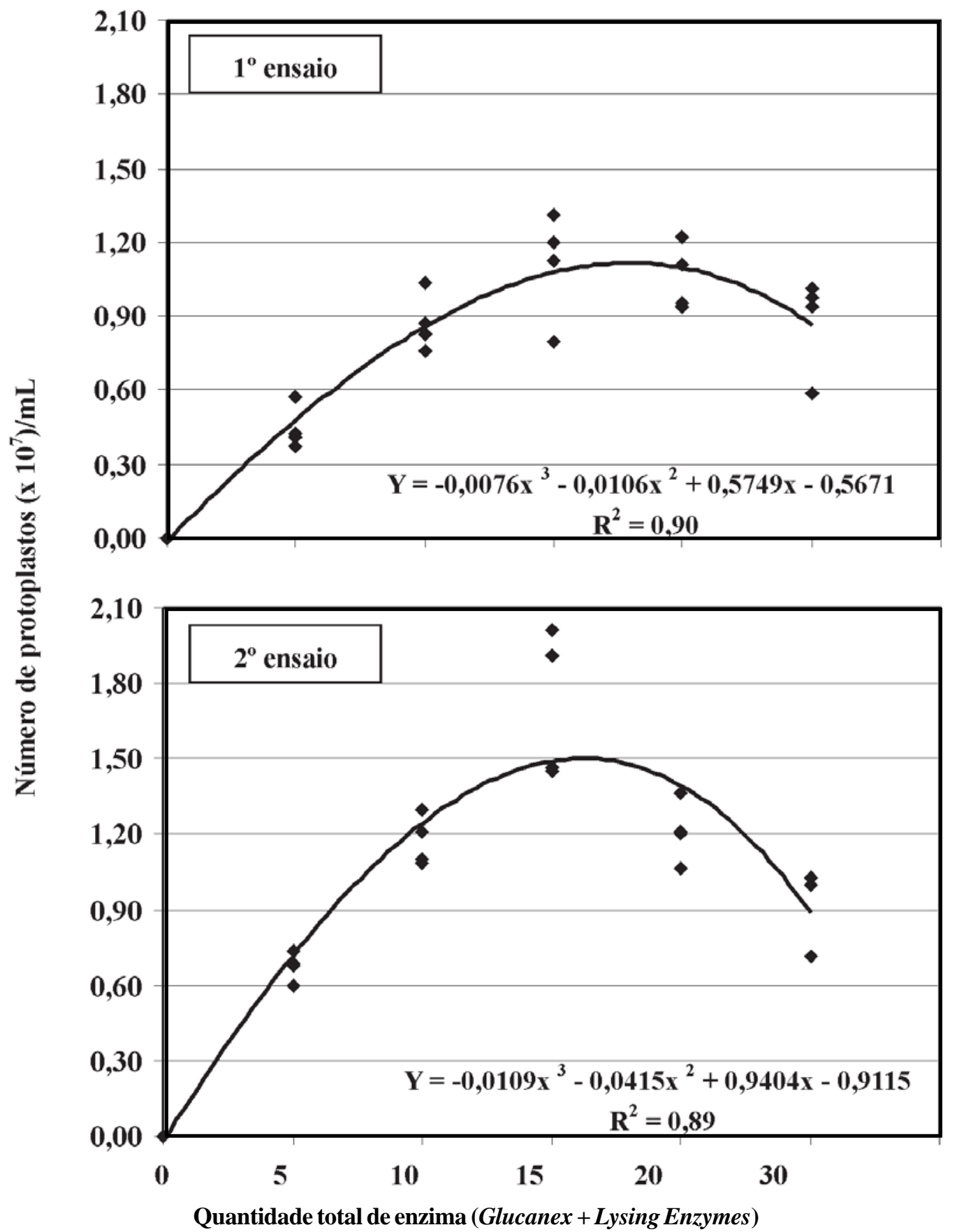

Figura 2 - Número de protoplastos de Botryosphaeria sp. em função da concentração de Glucanex e Lysing Enzymes. 
Tipos de estabilizadores osmóticos

O soluto usado no sistema lítico influenciou a protoplastização de Botryosphaeria sp. (Figura 3). Nos dois ensaios se observou a mesma tendência para a eficiência dos estabilizadores osmóticos. Maior liberação de protoplastos foi constatada com a solução $\mathrm{MgSO}_{4}$ a $1,2 \mathrm{M}$, em média $1,78 \times 10^{7}$ protoplastos/ $\mathrm{mL}$.

A estabilização proporcionada com $\mathrm{KCl}$ a 0,7M ou com $\mathrm{NaCl}$ a 0,8 $\mathrm{M}$ foram similares, porém menos eficiente do que a observada com $\mathrm{MgSO}_{4}$ a 1,2 M.
Duas soluções compostas por açúcares foram testadas para estabilizar osmoticamente a protoplastização do fungo. O uso de solução à base de sacarose ou sorbitol promoveu baixa produção de protoplastos, médias dos ensaios de 0,31 e 0,15 x 107/mL, respectivamente (Figura 3).

Embora não mensurados, protoplastos maiores foram observados ao microscópio óptico quando se usou estabilizadores salinos, especialmente $\mathrm{KCl}$ a 0,7 M. Por outro lado, soluções compostas por sorbitol ou sacarose produziram protoplastos menores.

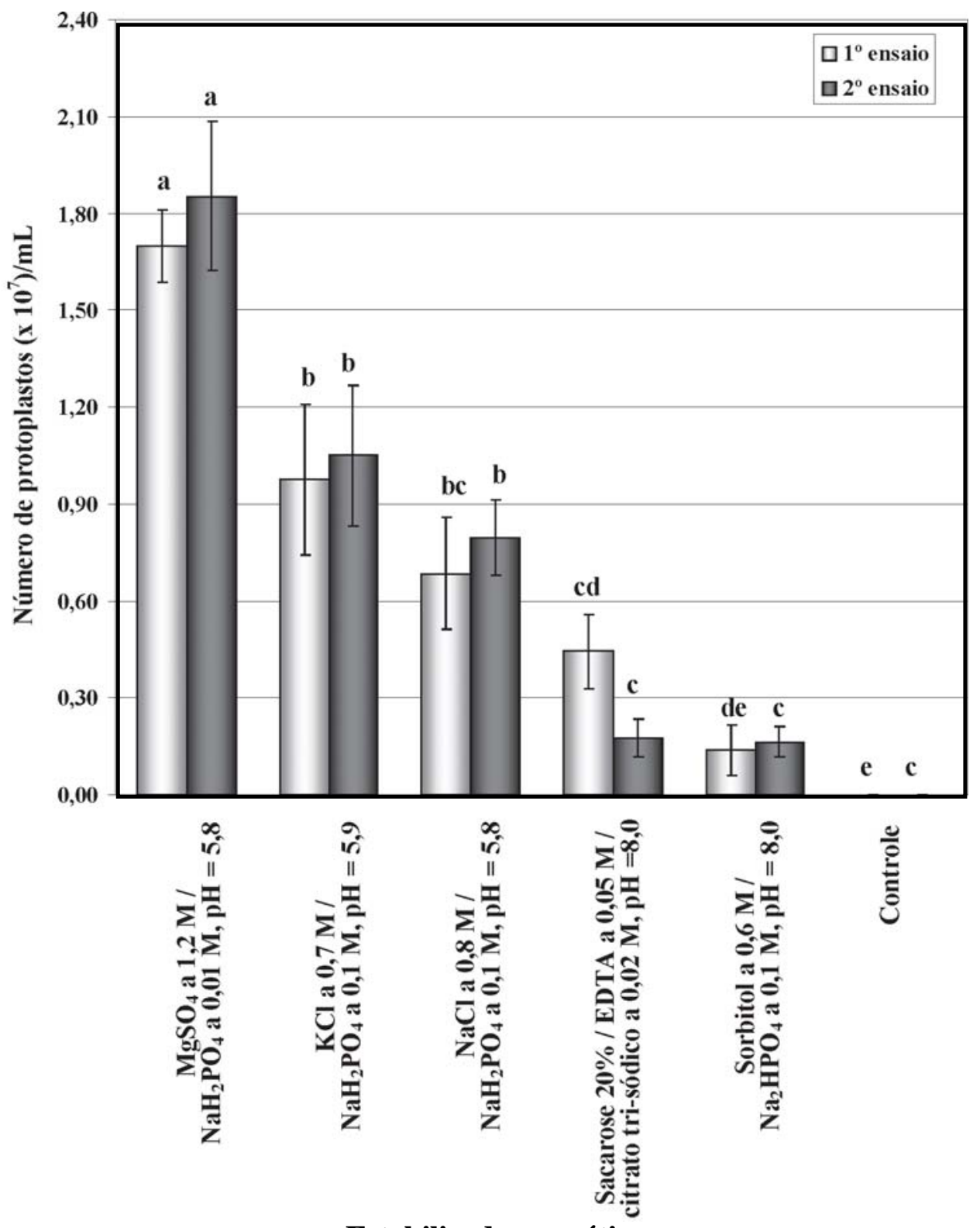

\section{Estabilizador osmótico}

Figura 3 - Número de protoplastos de Botryosphaeria sp. em função do estabilizador osmótico. Barras representam o desvio padrão. Em cada ensaio, tratamentos com mesma letra não diferem pelo teste de Tukey a 5\%. 
Tempos de exposição ao sistema enzimático

A protoplastização de Botryosphaeria sp. foi monitorada a cada 60 minutos, durante 6 horas de digestão, e em ambos os ensaios, protoplastos já foram observados com apenas 1 hora de incubação, porém em baixo número (Figura 4). Aumento considerável na liberação de protoplastos foi constatado a partir da segunda hora de incubação. As maiores produções de protoplastos foram registradas com 4 horas de digestão enzimática do micélio. Foram observados 1,50 e 1,70 x $10^{7}$ protoplastos/mL no primeiro e segundo ensaio, respectivamente. A partir da quarta hora de incubação, se observou redução na liberação de protoplastos em ambos os ensaios (Figura 4).

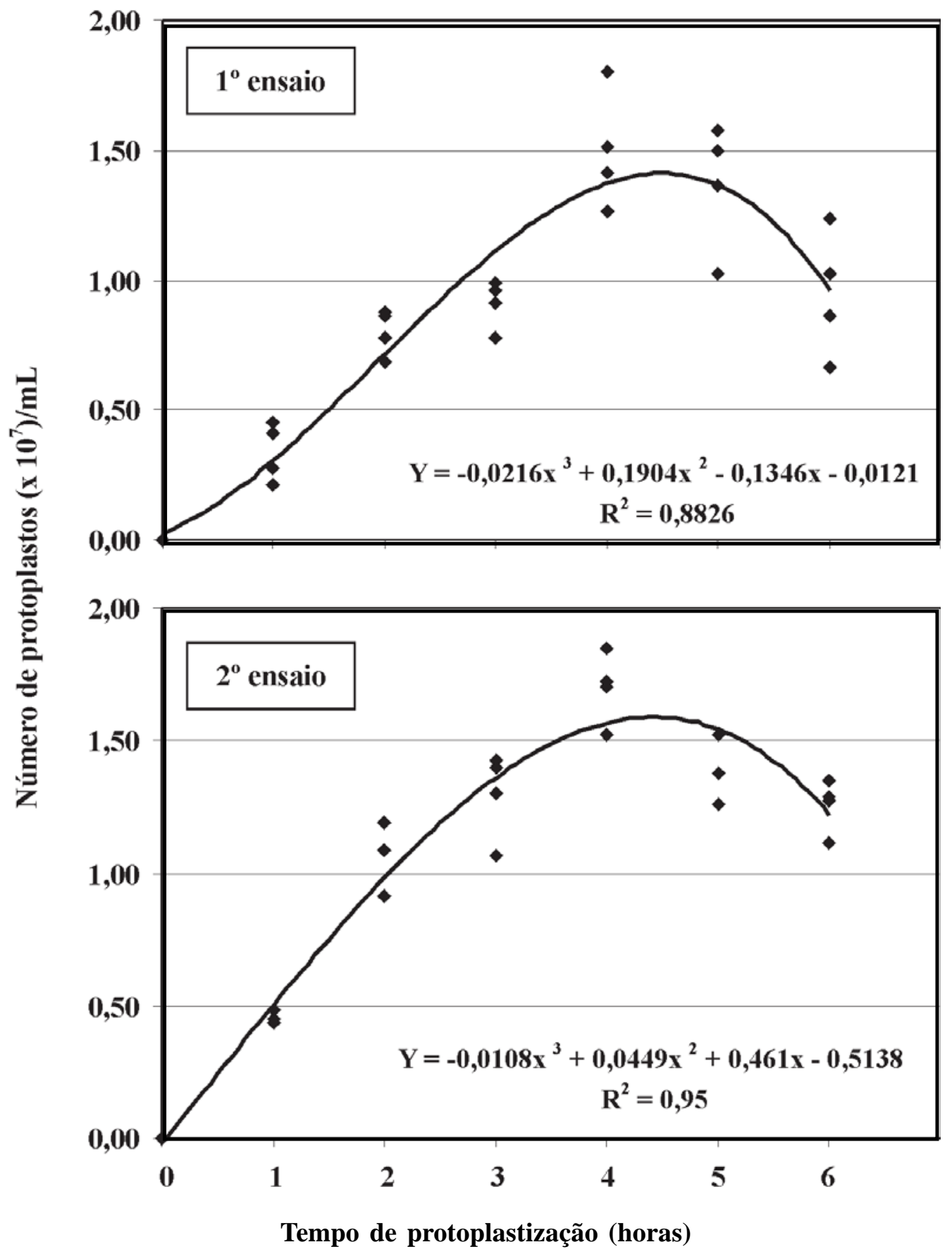

Figura 4 - Número de protoplastos de Botryosphaeria sp. em função do tempo de protoplastização. 
Na Figura 5 estão apresentados protoplastos de Botryosphaeria sp. obtidos com 4 horas de incubação do micélio em estabilizador osmótico $\mathrm{KCl}$ a 0,7 M/ $\mathrm{NaH}_{2} \mathrm{PO}_{4}$ a $0,1 \mathrm{M}(\mathrm{pH}=5,9)$ contendo $7,5 \mathrm{mg}$ de Glucanex e 7,5 mg de Lysing Enzymes.

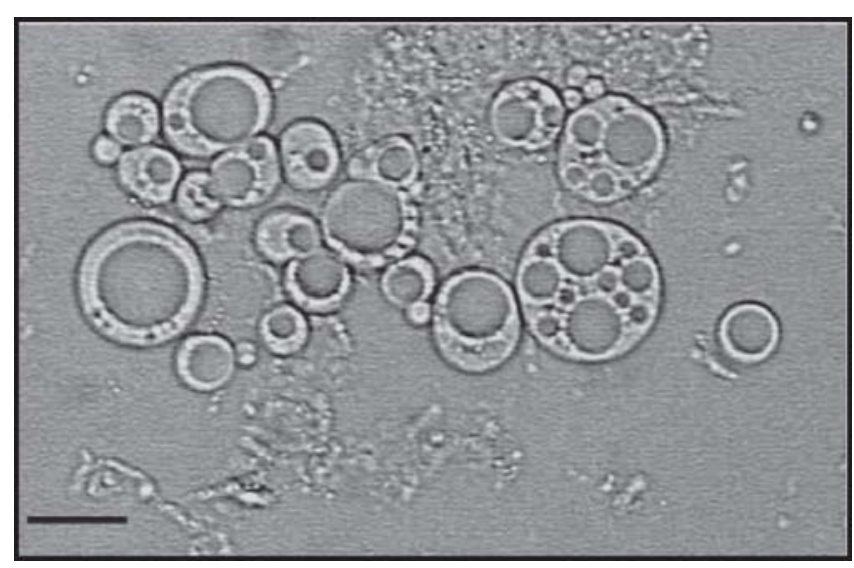

Figura 5 - Fotomicrografia de protoplastos de Botryosphaeria sp. Barra na parte inferior da figura corresponde a $10 \mu \mathrm{m}$.

\section{Discussão}

Os sistemas enzimáticos avaliados apresentaram variações consideráveis na liberação de protoplastos de Botryosphaeria sp. Isso era esperado, uma vez que a eficiência do complexo enzimático é dependente da composição da parede celular fúngica (Marchi, 2003).

Individualmente, Glucanex e Lysing Enzymes foram eficientes na obtenção de protoplastos de Botryosphaeria sp. Porém, o uso simultâneo de Glucanex e Lysing Enzymes resultou em aumentos expressivos na produção de protoplastos. Muitas vezes, devido à complexidade e diversidade da parede celular das hifas, a protoplastização de fungos filamentosos tem sido facilitada pelo enriquecimento de um complexo hidrolítico com outros complexos hidrolíticos (Hamlyn et al., 1981; Hashiba \& Yamada, 1982; Asai et al., 1986; Teraoka et al., 1992; Marchi et al., 2006). A eficiência superior das combinações de enzimas é supostamente devido à ação sinergística dos componentes líticos (Hashiba \& Yamada, 1982). É possível que a atuação de um complexo enzimático torne o substrato do outro complexo mais acessível.
Em contraste ao observado com a combinação Glucanex-Lysing Enzymes, a combinação de Cellulase Onozuka R10 com os complexos líticos Driselase, Lysing Enzymes ou Glucanex não foi adequada para potencializar a liberação de protoplastos. Pelo contrário, no caso de Glucanex-Cellulase Onozuka R10 houve redução na produção de protoplastos em relação à Glucanex isolada. É possível que tenha ocorrido atuação excessiva de uma das enzimas sobre o substrato disponibilizado pela outra.

No geral, o que se observou foi a baixa eficiência do complexo enzimático à base de celulase na protoplastização de Botryosphaeria sp., inclusive não havendo diferenças entre as duas formulações comerciais avaliadas. Da mesma forma, foi evidenciada baixa eficiência de Driselase na liberação de protoplastos do fungo. O desempenho inferior de celulases e de Driselase também tem sido relatado para outros fungos filamentosos, como por exemplo, Magnaporthe grisea (Asia et al., 1986; Marchi et al., 2006).

A hidrólise da parede celular é potencializada adequando-se a relação micélio/complexo lítico. A composição da parede celular condicionará a concentração da enzima ou o tempo de digestão para a maior liberação de protoplastos (Anunciação, 1989). A relação micélio/enzima testada variou de 2,7:1 a 16:1, e maior número de protoplastos foi observado com a relação 5,3:1. Sistemas líticos mais concentrados levaram à redução do número de protoplastos liberados. Tal redução foi atribuída à atividade enzimática excessiva sobre os protoplastos, o que levou ao rompimento da membrana plasmática.

O estabilizador osmótico é outro componente importante no processo de protoplastização, pois deve promover condições favoráveis para a atividade enzimática e, principalmente, após a remoção da parede celular, o soluto deve garantir a integridade da célula até a síntese da nova parede. Na protoplastização de Botryosphaeria sp., constatou-se que os estabilizadores salinos foram superiores aos estabilizadores compostos por açúcares. Efeito semelhante foi reportado para outros fungos fitopatogênicos (Dias et al., 1997; Marchi et al., 2006). Sais inorgânicos são preconizados como mais eficientes para a protoplastização de fungos filamentosos, enquanto açúcares ou açúcares-álcoois como mais apropriados para a liberação de protoplastos 
de leveduras (Lalithakumari, 1996). Contudo, é possível que o caráter mais ácido dos estabilizadores salinos tenha favorecido a protoplastização do fungo, uma vez que o pH é fator crítico para a produção de protoplastos, por influenciar a atividade do complexo enzimático e do estabilizador osmótico (Vega, 1990).

O tamanho dos protoplastos foi influenciado pelo estabilizador osmótico. Em geral, se observaram protoplastos maiores quando sais foram usados para compor as soluções. Segundo Peberdy \& Gibson (1971), indução ou aumento de vacúolos nos protoplastos pode ocorrer quando a estabilização é promovida por sais. Tal evento foi claramente observado quando se empregou a solução estabilizadora $\mathrm{KCl}$ a $0,7 \mathrm{M}$.

A liberação de protoplastos foi progressiva até a quarta hora de digestão enzimática do micélio. A partir daí, observou-se redução na produção de protoplastos. Segundo Kim et al. (2000), incubações prolongadas com enzimas líticas podem levar a degeneração dos primeiros protoplastos liberados.

Para que sejam funcionais nos estudos de fungos filamentosos, os protoplastos são requeridos em grande número $\left(\geq 10^{6} / \mathrm{mL}\right)$, e principalmente que apresentem boa capacidade regenerativa. Contudo, as taxas de regeneração e reversão são dependentes da espécie fúngica, em geral, não atingindo 100\% (Aguilar, 1991). Os protoplastos de Botryosphaeria sp., obtidos segundo o protocolo estabelecido, foram aptos a regenerar e reverter para a forma hifálica quando plaquedos em meio TB3, à base de sacarose (dados não apresentados). Contudo, a freqüência de regeneração e reversão dos protoplastos não tem sido quantificada. Vale ressaltar que hidrólise enzimática prolongada pode levar a produção de protoplastos com baixa capacidade regenerativa (Dias et al., 1996; Marchi et al., 2006).

Os protoplastos poderão constituir ferramentas biológicas valiosas para a melhor compreensão de Botryosphaeria spp., inclusive sendo úteis em eventuais programas de transformação e mutagênese.

\section{Conclusões}

Produção eficiente de protoplastos de Botryosphaeria sp. é alcançada com a combinação de enzimas Glucanex e Lysing Enzymes.
O uso simultâneo de 7,5 mg de Glucanex e 7,5 mg de Lysing Enzymes, em 3,5 mL de estabilizador osmótico, resulta em maior liberação de protoplastos de Botryosphaeria sp.

A solução $\mathrm{MgSO}_{4}$ a 1,2 M / NaH $\mathrm{PO}_{4}$ a 0,01 M $(\mathrm{pH}=5,8)$ constitui o estabilizador osmótico mais eficiente para a protoplastização de Botryosphaeria sp.

Maior liberação de protoplastos de Botryosphaeria sp. é observada com quatro horas de digestão enzimática.

\section{REFERÊNCIAS}

1. AGUILAR, M.B.D. Atividade celulolítica e protoplastização em Humicola sp. e Trichoderma pseudokoningii var. rifai. Piracicaba. 1991. 112p. Tese (Doutorado em Genética e Melhoramento de Plantas) - Escola Superior de Agricultura Luiz de Queiroz/Universidade de São Paulo.

2. ANUNCIAÇÃO, C.E. Obtenção e regeneração de protoplastos do fungo micorrízico Pisolithus tinctorius. Viçosa. 1989. 57p. Dissertação (Mestrado em Microbiologia Agrícola) - Universidade Federal de Viçosa.

3. ASAI, T.; OKUNO, T.; MATSUURA, K. Isolation and germination type of protoplasts of spores and hyphae of Pyricularia oryzae. Annals of the Phytopathological Society of Japan, v.52, p.843-849, 1986.

4. DIAS, E.S.; ARAÚJO, E.F.; GUIMARÃES, W.V.; MUCHOVEJ, R.M.C. Production and regeneration of protoplasts from the mycorrhizal fungus Suillus granulatus. World Journal of Microbiology \& Biotechnology, v.12, p.625628, 1996.

5. DIAS, E.S.; ARAÚJO, E.F.; GUIMARÃES, W.V.; COELHO, J.L.C.; SILVA, D.O. Production and regeneration of Penicillium expansum and Penicillium griseoroseum protoplasts. Revista de Microbiologia, v.28, p.116-120, 1997.

6. HAMLYN, P.F.; BRADSHAW, R.E.; MELLON, F.M.; SANTIAGO, C.M.; WILSON, J.M.; PEBERDY, J.F. Efficient protoplast isolation from fungi using commercial enzymes. Enzyme and Microbial Technology, v.3, p.321-325, 1981.

7. HASHIBA, T.; YAMADA, M. Formation and purification of protoplasts from Rhizoctonia solani. Phytopathology, v.72, p.849-853, 1982.

8. KIM, B.K.; KANG, J.H.; JIN, M.; KIM, H.W.; SHIM, M.J.; CHOI, E.C. Mycelial protoplast isolation and regeneration of Lentinus lepideus. Life Sciences, v.66, p.1359-1367, 2000.

9. KRUGNER, T.L.; AUER, C.G. Doenças do eucalipto. In: KIMATI, H.; AMORIM, L.; BERGAMIN FILHO, A.; CAMARGO, L.E.A.; REZENDE, J.A.M. Manual de Fitopatologia, v.2, São Paulo: Ceres, 1997. p.358-375. 
10. LALITHAKUMARI, D. Protoplasts - a biotechnological tool for plant pathological studies. Indian Phytopathology, v.49, p.199-212, 1996.

11. MARCHI, C.E. Mutantes insercionais de Magnaporthe grisea com patogenicidade alterada em arroz. Viçosa. 2003. 136p. Tese (doutorado em Fitopatologia) - Universidade Federal de Viçosa.

12. MARCHI, C.E.; BROMMONSCHENKEL, S.H.; QUEIROZ, M.V. DE; MIZUBUTI, E.S.G. Obtenção e regeneração de protoplastos de Magnaporthe grisea. Summa Phytopathologica, v. 32, p.232-238, 2006.

13. PEBERDY, J.F.; GIBSON, R.K. Regeneration of Aspergillus nidulans protoplasts. Journal of General Microbiology, v. 69, p.325-330, 1971.

14. SILVEIRA, R.L.V.DE A.; GONÇALVES, A.N.; KRÜGNER, T.L. Estado nutricional de Eucalyptus citriodora Hook cultivado sob diferentes doses de boro e sua relação com a agressividade de Botryosphaeria ribis. Scientia Forestalis, v.53, p.57-70, 1998.

15. SILVEIRA, R.L.V. DE A.; HIGASHI, E.N. Aspectos nutricionais envolvidos na ocorrência de doenças com ênfase para o eucalipto. Circular Técnica IPEF, n.200, 2003. 14p.

16. SLIPPERS, B.; FOURIE, G.; CROUS, P.W.; COUTINHO, T.A.;WINGFIELD, B.D.; CARNEGIE, A.J.; WINGFIELD, M.J. Speciation and distribution of Botryosphaeria spp. on native and introduced Eucalyptus trees in Australia and South Africa. Studies in Mycology, p.50, p.343-358, 2004.

17. TERAOKA, T.; SHIMURA, Y.; HOSOKAWA, D.; WATANABE, M. Giant protoplasts of Pyricularia oryzae Cavara. Annals of the Phytopathological Society of Japan, v.58, p.726-733, 1992.

18. TPCP. The Tree Protection Cooperative Programme of FABI (Forestry and Agricultural Biotechnology Institute). Botryosphaeria canker and die-back of Eucalyptus. 2002. Disponível em: <http://www.up.ac.za/academic/fabi/tpcp/ pamphlets/pdf/botryosphaeria. pdf>. Acesso em: 20 abr. 2006.

19. VEGA, M.E. Aspectos genéticos da parameiose via fusão de protoplastos em Metarhizium anisopliae (Metsch.) Sorokin. Piracicaba. 1990. 95p. Dissertação (Mestrado em Genética e Melhoramento de Plantas) - Escola Superior de Agricultura Luiz de Queiroz/Universidade de São Paulo. 